\title{
Clinical Characteristics and Mortality of Obstetric Patients Admitted to a Tertiary Intensive Care Unit in the Brazilian Northeast
}

\author{
Orivaldo Alves Barbosa ${ }^{1 *}$, Rafhaela Monteiro de Lima ${ }^{2}$, Renata Caetano Aguiar ${ }^{2}$, Mariana Gabriella \\ Correia Viana ${ }^{2}$
}

\begin{abstract}
Objectives: This study aimed to analyze the determinants of hospitalization and death in an intensive care unit (ICU) between pregnant and postpartum women.

Materials and Methods: This is a quantitative and retrospective documentary research performed at Dr. César Cals Hospital. Data was collected through the analysis of charts obtained from puerperal or pregnant women admitted to the ICU.

Results: Regarding the type of delivery, 41 (73.2\%) women had a cesarean section (CS) and, considering the outcome, the majority of the patients $(51 \%)$ were discharged from the hospi-tal. Comparing the admission diagnosis and the outcome, it was revealed that many patients presented more than one diagnosis at the admission, the highest rate of which was the hyper-tensive disorders of pregnancy (HDP) and complications comprising of 23 (38.3\%) patients out of which 4 of them died. Sepsis was the second cause of hospitalization including 17 (28.3\%) patients. In addition, 11 (18.3\%) patients had hemorrhaged. Moreover, there were 2 death reports related to fulminant hepatitis.

Conclusions: It is expected that the results of the present study contribute to the extension of the professionals' knowledge on the subject, collaborating to prevent hospitalization and death of these patients.

Keywords: ICU, Pregnancy complications, Maternal mortality, HDP, Sepsis
\end{abstract}

\section{Introduction}

According to the World Health Organization (WHO), maternal mortality is determined as death during pregnancy or puerperium (up to 42 days postpartum), being related to obstetric complications or exacerbation of preexisting conditions complicated by pregnancy $(1,2)$. In developing countries, such as Brazil, most deaths occur as a result of direct obstetric causes, usually related to a deficiency in peripartum care (3).

According to WHO statistics, among the main causes of maternal death worldwide (between 1997 and 2002 related to the causes of direct death), hemorrhage was the most important in Africa while hypertensive syndromes and abortion were more prevalent in Latin America. In Brazil, for instance, hypertensive syndromes accounted for $20 \%$ to $30 \%$ of all the maternal deaths followed by obstetric hemorrhage (10\%-20\%), and infections (less than $10 \%$ of the deaths) $(1,2,4)$.

Considering the different etiologies related to complications leading to the intensive care unit (ICU) pregnancy, preeclampsia/eclampsia should be highlighted. Thus, it was suggested that intensive care (IC)management for women with this condition can result in a better outcome and a consequent improvement in the maternal mortality rate. Admission to the ICU may be for organ support, intensive monitoring, mechanical ventilation, or management of complications (5).

Regions with high rates of maternal mortality need immediate action. However, these are the areas where there are the least reliable studies on the subject. It is worrying that maternity indicators occasionally show an illusory reality in Brazil: low maternal mortality rates compared to the developed countries (6). This is possibly due to the loss of follow-up the patients when admitted to the ICU.

In the international literature, there are few studies regarding the IC or transfers to ICU in Obstetrics. Since 1990, technical equipment resources are considered fundamental in these special types of units, since most of the pregnant women referred to the ICU are in a critical condition and at the risk of death, requiring a specialized treatment that allows the early detection of diseases and prophylaxis of its complications (6).

A key requirement for further advances in the reduction of maternal deaths is to understand the causes of deaths for better healthcare planning. The present study sought

Received 19 December 2017, Accepted 12 June 2018, Available online 1 July 2018

${ }^{1}$ Christus University (UNICHRISTUS), Fortaleza-CE, Brazil. ${ }^{2}$ Christus University (UNICHRISTUS), R. João Adolfo Gurgel, 133 - Cocó, Fortaleza - CE, 60190-060, Brazil.

*Corresponding Author: Orivaldo Alves Barbosa, MD, Fax: +5585 31015333, Tel: +5585 81817009, Email: orivaldo.alves.barbosa@gmail.com 
to analyze the determining factors for the hospitalization and death of pregnant and postpartum women in ICU enabling continued planning, education, and reallocation of resources in a resource-poor setting.

\section{Materials and Methods}

This was a quantitative and retrospective documentary research conducted at Public Hospital of the Ceará State SESA/CE -General Hospital of Dr. César Cals (HGCC), which is a reference service in Gynecology, Obstetrics, and Neonatology in the State of Ceará equipped with 2 adult ICUs each with 6 beds.

All medical records of the patients admitted to the maternal ICU for obstetrical reasons were selected during March 2014 to June 2017. Patients in pregnancy at any gestational or puerperal age were included in the study and those with unreadable medical records or incomplete information were excluded. Data were collected analyzing the charts obtained from the HGCC for the puerperal or pregnant women hospitalized in ICUs, based on the variables that were determinant for the study. The data were then recorded as a collection developed by the researchers.

The analyzed variables were as follows: (1) patients identification, that is, their age, color, marital status, origin, and pre-gestational comorbidities; (2) gestational age, number of consultations and prenatal care, type of delivery, APACHE (acute physiology and chronic health evaluation) II of hospitalization, priority for ICU, outcome, mechanical ventilation needs, advanced monitoring and vasoactive drug, and causes of ICU admission (i.e., hemorrhage/coagulation disseminated intravascular (CIVD), thrombosis/pulmonary thromboembolism (PE), sepsis, peripartum cardiomyopathy/maternal cardiopathy, thrombotic microangiopathy, fulminant hepatitis/ acute fatty liver of pregnancy hypertensive disease and complications, and adult respiratory distress syndrome).

The data were organized and processed by the Statistical Package for the Social Sciences (SPSS) software, version 17. Besides, the analysis was conducted adopting 95\% CI. Besides, the categorical data were expressed as absolute and percentage frequency and cross-checked using Fisher exact test or chi-square. Values of $P<0.05$ were considered statistically significant. In addition, a comparative analysis was performed between the death and hospital discharge outcomes in order to determine the main factors associated with maternal death.

\section{Results}

Regarding the clinical and epidemiological aspects, 32 $(53.3 \%)$ patients were in the age range up to 25 years, 31 (51.7\%) of them were from Fortaleza, and 28 (46.7\%) of the patients performed at least 6 prenatal visits. Considering the type of delivery, 41 (73.2\%) were cesareans and most of the pregnancies were term or preterm. And finally, with regard to the outcome, the majority of the patients (51\%) were discharged from the hospital.

In the analysis between the admission diagnosis and the outcome, it was observed that many patients presented more than one admission diagnosis, the highest rate being hypertensive disorders of pregnancy (HDP) and the related complications comprising 23 (38.3\%) women out of which four patients died. Sepsis was the second cause of hospitalization with $17(28.3 \%)$ patient women. In addition, 11 (18.3\%) patients suffered a hemorrhage. The result related to fulminant hepatitis 0.056 was significant at $P<0.056$. Two patients died of fulminant hepatitis. The related results are provided in Tables 1 and 2 .

Concerning the factors influencing the outcome of the patients, it was found that of the 51 patients discharging from the ICU, 11 and 41 of them underwent normal and cesarean delivery, respectively. In addition, according to the reports, all the patients who died had a cesarean delivery. With respect to admission diagnosis, most patients who died had HDP, their complications and sepsis, with a total number of 4 (44.4\%).

Regarding the score, according to the APACHE II, $60 \%$ of the patients obtained up to $16 \%$ and $28.3 \%$ greater than 16 points.

\section{Discussion}

Admissions for obstetric causes represent an important group of patients in the ICU since they require specialized care and specific knowledge of physiological changes specific to pregnancy, which may interfere with the decision-making. As a result, pregnancy frequently aggravates clinical conditions and affects the interpretation of diagnostic and laboratory tests (3).

In the current study, patients in the ICU were mostly adult and young ( $<25$ years), corresponding to $53.3 \%$ a

Table 1. Correlation Between Admission Diagnosis and Outcome

\begin{tabular}{|c|c|c|c|c|}
\hline \multirow{2}{*}{ Diagnosis on Admission Discharge } & \multicolumn{3}{|c|}{ Outcome } & \multirow[b]{2}{*}{$P$ Value } \\
\hline & Total & Hospital & Death & \\
\hline Hypertension and complications & $23(38.3 \%)$ & $19(37.3 \%)$ & $4(44.4 \%)$ & 0.721 \\
\hline Sepsis & $17(28.3 \%)$ & $13(25.5 \%)$ & $4(44.4 \%)$ & 0.256 \\
\hline Peripartum cardiomyopathy & $14(23.3 \%)$ & $14(27.5 \%)$ & $0(0 \%)$ & 0.1 \\
\hline Hemorrhage & $11(18.3 \%)$ & $8(15.7 \%)$ & $3(33.3 \%)$ & 0.345 \\
\hline Thrombotic microangiopathy & $6(10 \%)$ & $5(9.8 \%)$ & $1(11.11 \%)$ & 1 \\
\hline Fulminant hepatitis & $3(5 \%)$ & $1(2.0 \%)$ & $2(22.2 \%)$ & 0.056 \\
\hline Thrombus & $2(3.3 \%)$ & $2(3.9 \%)$ & $0(0 \%)$ & 1 \\
\hline
\end{tabular}


Table 2. Outcome of the Patients Hospitalized in ICU

\begin{tabular}{|c|c|c|}
\hline Variable & $\begin{array}{l}\text { Death } \\
n=9\end{array}$ & $\begin{array}{l}\text { Hospital Discharge } \\
n=51\end{array}$ \\
\hline \multicolumn{3}{|l|}{ Age group (y) } \\
\hline Up to 25 & $5(55.6)$ & $27(52.9)$ \\
\hline Older than 25 & $4(44.4)$ & $24(47.1)$ \\
\hline \multicolumn{3}{|l|}{ Origin } \\
\hline Capital (Fortaleza) & $5(55.6)$ & $26(51.0)$ \\
\hline Countryside & $4(44.4)$ & $20(39.2)$ \\
\hline \multicolumn{3}{|l|}{ Prenatal } \\
\hline 6 Medical appointments & $3(33.3)$ & $6(11.8)$ \\
\hline More than 6 & $2(22.2)$ & $17(33.3)$ \\
\hline Less than 6 & $3(33.3)$ & $12(23.5)$ \\
\hline No record & $1(11.1)$ & $16(31.4)$ \\
\hline \multicolumn{3}{|l|}{ Type of birth } \\
\hline Normal & $0(0)$ & $11(23.4)$ \\
\hline Cesarian & $9(100)$ & $32(68.1)$ \\
\hline No medical data & $0(0)$ & $4(8.5)$ \\
\hline \multicolumn{3}{|l|}{ Diagnosis of admission } \\
\hline HYP \& complications & $4(44.4)$ & $19(37.3)$ \\
\hline Sepsis & $4(44.4)$ & $13(25.5)$ \\
\hline Peripartum cardiopathy & $0(0)$ & $14(27.5)$ \\
\hline Hemorrage & $3(33.3)$ & $8(15.7)$ \\
\hline Thrombotic microangiopathy & $1(11.1)$ & $5(9.8)$ \\
\hline Fulminant hepatitis & $2(22.2)$ & $1(2.0)$ \\
\hline Thrombus & $0(0)$ & $2(3.9)$ \\
\hline \multicolumn{3}{|l|}{ Gestational age } \\
\hline AT term & $4(44.4)$ & $21(44.7)$ \\
\hline Pre-term & $5(55.6)$ & $19(40.4)$ \\
\hline Post-term & $0(0)$ & 7 (14.9) \\
\hline \multicolumn{3}{|l|}{ APACHE II } \\
\hline Up to 16 points & $4(11.1)$ & $32(88.9)$ \\
\hline Over 16 points & $5(29.4)$ & $12(70.6)$ \\
\hline \multicolumn{3}{|l|}{ Mechanical ventilation } \\
\hline Yes & $8(88.9)$ & $11(22.0)$ \\
\hline No & $1(11.1)$ & $39(78.0)$ \\
\hline
\end{tabular}

result similar to a retrospective analysis in which $59.6 \%$ of the patients were less than 25 years old (6).

Concerning prenatal care, $25 \%$ of the patients performed less than six consultations during their pregnancy under the recommended minimum as stated by the Brazilian National Ministry of Health. In one study (7), 41\% of the women had 4 to 6 consultations while $12 \%$ of them had none. The high incidence of patients with a low number of prenatal visits is worrisome and may help in understanding the high mortality rate in this group.

Cesarean section (CS) represented the majority of childbirths. Vaginal parturition occurred in $19.6 \%$ and CS in $73.2 \%$ of the women. This is similar to what was found in a study in Turkey (8) where $90 \%$ of the sample underwent a CS. The high number of CSs may have revealed both the severity of the obstetric diseases under analysis and a possible need for rapid discontinuation of these critical pregnancies. In general, cesarean delivery is identified as the best option when there is deterioration of the maternal clinical picture or fetal vitality. According to the literature data, CS is an important risk factor for maternal deaths, which corroborates with the finding of the present study, in which all the pregnant women who died had undergone cesarean procedure $(9,10)$.

In addition, as regards gestational age, there was a considerable approximation between the "term" and the "preterm", respectively ( $44.6 \%$ vs. $42.9 \%$ ). However, there was a higher death rate in pregnant women with preterm gestational age. In 2017, a study conducted in Turkey (8), reported that the average gestational age was 35 weeks, similar to other studies conducted in China $(9,10)$. This fact indicates that women with clinical diseases tend to have complications at a later stage of gestation. It is therefore justified in this group, more intense prenatal care, especially in the third trimester (11).

The only pre-gestational comorbidity identified among the patients was related to heart disease and $100 \%$ of the patients were discharged. In contrast, in the United Kingdom, a higher prevalence of cardiac disease was identified among patients who died, demonstrating regional specific characteristics of each health service (12). Cardiac disease is considered as the main cause of indirect obstetric hospitalization (13).

In the present study, $38.3 \%$ of the patients indicated hypertension as a diagnosis of admission to the ICU. In a systematic review of the literature during 1990-2008, the hypertensive syndrome was found to be the most prevalent in a specific obstetric cause for hospitalization $(5,14)$ Hypertensive gestational syndromes including chronic hypertension and the entire spectrum of preeclampsia, complicated about $7 \%$ of the pregnancies. Moreover, deaths related to this clinical condition have been constantly reported, often ranging from 1 to $24 \%$ (15). In the current study, mortality rate (44.4\%) was higher than that of expected in the available literature.

The main causes of complications related to pregnancy were as follows: severe hemorrhage after the childbirth, infections, pregnancy-induced hypertension, and unsafe abortion $(1,2,16)$. Besides, sepsis was the second leading cause of hospitalization in the study (28.3\%), representing $44.4 \%$ of the patients who died. This result was similar to the percentage of patients hospitalized for hypertension.

There are some predisposing factors for sepsis in pregnancy such as CS, lack of prenatal care, abortion induction, premature rupture of the placental membrane, and conditions inherent to the obstetric population $(15,16)$.

In patients with fulminant hepatitis, $22 \%$ of them died $(P<0.05)$. Although a rare clinical condition was 
observed since the vaccination for hepatitis A and B, there were higher than expected cases of death due to hepatic disease in the population of the current study. This may demonstrate the carelessness of pregnant women in relation to their health condition $(9,17)$.

Among 15\% of the patients who died, the majority of them (88.9\%) required using vasoactive drugs and mechanical ventilation (MV). In a cohort of an Argentine ICU, there was a need for MV in $85 \%$ of the patients and the use of vasoactive drugs was observed in $56 \%$ of them. In addition, in a US study, $92 \%$ of the women patients used vasoactive drugs while $63 \%$ of them employed VM $(18,19)$.

As for APACHE II, $29.4 \%$ of the pregnant women (APACHE II greater than 16 points) died. The APACHE II is a point assessment system ranging from 0 to 71 points, which arise from the need to classify groups of patients admitted to the ICU. It is based on the severity of the disease and the estimated risk of death through standardized information. For its calculation, the worst results for each of the variables in the first 24 hours of ICU stay, the age, and the presence of previous chronic disease should be considered. Its application requires a minimum of 24 hours of patient hospitalization. According to the results, it was inferred that APACHE II was predictive of estimating the severity of the disease and predicting the hospital mortality of the pregnant women under study.

In every human attempt, no doubt, there exist some limitations and problems which need to be acknowledged.

The medical records did not contain all the necessary data. The lack of information on financial income, education, and pathogens related to the cause of sepsis, for example, was a negative factor. If health professionals want to ensure a good understanding of the reasons for maternal hospitalization in ICU, then they cannot overlook the importance of sepsis. Therefore, including the required data on sepsis would add validity to the findings. As a result, similar studies focusing on this issue are subject to further investigation.

The data were collected from a single center which means that the results may not be generalized to other contexts. However, since Dr. César Cals Hospital is a hospital with a reference service in Gynecology, Obstetrics, and Neonatology for the State of Ceará, it is considered that the results are also applicable to other institutions and that they can contribute to the reduction of maternal mortality in a poor resource area in Brazil.

\section{Conclusions}

This study was an effort to investigate the determinants of hospitalization and death in ICU between pregnant and postpartum women. The main causes of hospitalization in intensive care in our obstetric population were hypertensive diseases, sepsis, obstetric bleeding and maternal cardiopathy. The Apache 2 score was a good predictor of mortality in this population. Based on the findings, planning and training meetings can be conducted for health professionals, that is, nurses, obstetricians, and IC physicians to increase their knowledge about the main pathologies responsible for hospitalization and maternal death in ICU.

\section{Conflict of Interests}

Authors declare that they have no conflict of interests.

\section{Ethical Issues}

The study was evaluated and approved by the Research Ethics Committee of the HGCC under the approval number of 1.628.549 in the Brazilian National Research Platform.

\section{Financial Support}

The authors did not receive financial support from government or any private institution.

\section{References}

1. Alkema L, Chou D, Hogan D, et al. Global, regional, and national levels and trends in maternal mortality between 1990 and 2015, with scenario-based projections to 2030: a systematic analysis by the UN Maternal Mortality Estimation Inter-Agency Group. Lancet. 2016;387(10017):462-474. doi:10.1016/s0140-6736(15)00838-7

2. Say L, Chou D, Gemmill A, et al. Global causes of maternal death: a WHO systematic analysis. Lancet Glob Health. 2014;2(6):e323-333. doi:10.1016/s2214-109x(14)70227-x

3. Laurenti R, Jorge MHPM, Gotlieb SL. A mortalidade materna nas capitais brasileiras: algumas características e estimativa de um fator de ajuste. [Maternal mortality in Brazilian State Capitals: some characteristics and estimates for an adjustment factor]. Rev Bras Epidemiol. 2004;7(4):449-460. doi:10.1590/S1415-790X2004000400008

4. Morse ML, Fonseca SC, Barbosa MD, Calil MB, Eyer FP. [Maternal mortality in Brazil: what has the scientific literature shown in the last 30 years?]. Cad Saude Publica. 2011;27(4):623-638. doi:10.1590/S0102$311 X 2011000400002$

5. Imarengiaye CO, Isesele TO. Intensive care management and outcome of women with hypertensive diseases of pregnancy. Niger Med J. 2015;56(5):333-337. doi:10.4103/0300-1652.170389

6. Viggiano MB, Viggiano MG, de Souza E, Camano L. Necessidade de cuidados intensivos em maternidade pública terciária. [Necessity of intensive care in a tertiary public maternity hospital]. Rev Bras Ginecol Obstet. 2004;26(4):317-323. doi:10.1590/S010072032004000400009

7. Novo JL, Gianini RJ. Mortalidade materna por eclâmpsia. [Eclampsia as a cause of maternal mortality]. Rev Bras Saude Mater Infant. 2010;10(2):209-217. doi:10.1590/ S1519-38292010000200008

8. Ranjan A, Sridhar STK, Matta N, Chokkakula S, Ansari RK. Prevalence of UTI among Pregnant Women and Its Complications in Newborns. Indian J Pharm Pract. 
2017;10(1):45-49. doi:10.5530/ijopp.10.1.10

9. Nove A, Matthews Z, Neal S, Camacho AV. Maternal mortality in adolescents compared with women of other ages: evidence from 144 countries. Lancet Glob Health. 2014;2(3):e155-164. doi:10.1016/s2214-109x(13)70179-7

10. Ye J, Zhang J, Mikolajczyk R, Torloni MR, Gulmezoglu AM, Betran AP. Association between rates of caesarean section and maternal and neonatal mortality in the 21 st century: a worldwide population-based ecological study with longitudinal data. BJOG. 2016;123(5):745-753. doi:10.1111/1471-0528.13592

11. Alkema L, Chou D, Hogan D, et al. Global, regional, and national levels and trends in maternal mortality between 1990 and 2015, with scenario-based projections to 2030: a systematic analysis by the UN Maternal Mortality Estimation Inter-Agency Group. Lancet. 2016;387(10017):462-474. doi:10.1016/s0140-6736(15)00838-7

12. Nair M, Kurinczuk JJ, Brocklehurst P, Sellers S, Lewis G, Knight M. Factors associated with maternal death from direct pregnancy complications: a UK national case-control study. BJOG. 2015;122(5):653-662. doi:10.1111/14710528.13279

13. de Souza Mde L, Laurenti R, Knobel R, Monticelli M, Bruggemann OM, Drake E. Maternal mortality due to hemorrhage in Brazil. Rev Lat Am Enfermagem. 2013;21(3):711-718. doi:10.1590/s010411692013000300009
14. Guerreiro DD, Borges WD, Nunes HH, da Silva SC, Maciel Jde P. Mortalidade materna relacionada à doença hipertensiva especifica da gestação (DHGE) em uma maternidade no Pará. Rev Enferm UFSM. 2014;4(4):825834. doi:10.5902/2179769213159

15. Gombar S, Ahuja V, Jafra A. A retrospective analysis of obstetric patient's outcome in intensive care unit of a tertiary care center. J Anaesthesiol Clin Pharmacol. 2014;30(4):502507. doi:10.4103/0970-9185.142843

16. El-Abd H, Mashhour K, Mwafy A. Clinical characteristics and outcomes of obstetric patients requiring ICU admission. Crit Care. 2011;15(1):P513. doi:10.1186/cc9933

17. Amaral TLM, Prado PR, Monteiro GTR, Ribeiro TS, Mendonca DP. Hepatite B e C na gestação: características maternas e neonatais. [Hepatitis $\mathrm{B}$ and $\mathrm{C}$ in pregnancy: features maternal and neonatal]. Rev Interdiscip. 2015;8(3):143-150.

18. Rios FG, Risso-Vazquez A, Alvarez J, et al. Clinical characteristics and outcomes of obstetric patients admitted to the intensive care unit. Int J Gynaecol Obstet. 2012;119(2):136-140. doi:10.1016/j.ijgo.2012.05.039

19. Cartin-Ceba R, Gajic O, Iyer VN, Vlahakis NE. Fetal outcomes of critically ill pregnant women admitted to the intensive care unit for nonobstetric causes. Crit Care Med. 2008;36(10):2746-2751. doi:10.1097/ CCM.0b013e318186b615

(C) 2019 The Author (s); This is an open-access article distributed under the terms of the Creative Commons Attribution License (http://creativecommons.org/licenses/by/4.0), which permits unrestricted use, distribution, and reproduction in any medium, provided the original work is properly cited. 